\title{
Analisa Tebal Bidang Tembus Gelombang Elektromagnetik USB WiFi LV-UW03
}

\author{
Dwi Priyokusumo, ST, MT ${ }^{1)}$; Drs. Rum Sapundani, $\mathbf{M S i}^{2}$; Irfan Helmanto, ST $^{3}$ \\ 1,2,3) Institut Teknologi dan Kesehatan Jakarta \\ Jl. Jatiwaringin Raya No. 278 Pondok Gede 17411, Jakarta \\ Telp: 021-846-1155, Fax: 021-846-3692 \\ website: itkj.ac.id \\ email: ${ }^{1)}$ dwipriyo@itkj.ac.id, ${ }^{2)}$ rumsapundani@itkj.ac.id, ${ }^{3)}$ irfan@itkj.ac.id
}

\begin{abstract}
ABSTRAK
Banyak alat elektronik pada zaman Industri 4.0 pada perangkat komunikasi memanfaatkan gelombang elektromagnet dapat terkoneksi dengan internet menggunakan media tanpa kabel atau sering disebut wireless fidelty (WiFi). Permasalahan yang terjadi antara pemancar sinyal WiFi (transmitter) dengan pengguna (receiver) terkoneksi dengan kekuatan sinyal berbeda - beda dikarenakan adanya penghalang pada suatu ruangan seperti kayu, kaca, dan coran/beton. Pengujian menggunakan USB WiFi LV-UW03 sebagai transmitter dan receiver dengan jarak Ocm pada bidang penghalang dengan variabel ketebal berbeda - beda, ketebalan kayu: 0,6cm, 1,2cm, dan 2cm, untuk kaca dengan ketebalan 0,3cm, 0,6cm, dan $1 \mathrm{~cm}$, sedangkan untuk bidang cor/beton dengan ketebalan $5 \mathrm{~cm}, 10 \mathrm{~cm}$, dan $15 \mathrm{~cm}$. Bertujuan menganalisa agar mengetahui berapa hambatan yang dilalui oleh gelombang elektromagnet dengan massa jenis bidang yang berbeda. Setelah melakukan ujicoba dapat dihasilkan; untuk bidang penghalang kayu memiliki redaman -3,6dB, -4,2dB, dan -7,6dB; untuk bidang penghalang kaca memiliki redaman $6,5 d B,-10 d B$, dan -12,1dB; sedangkan pada bidang penghalang coran/beton -9,2dB, -14,3dB dan -19,3dB. Kesimpulan pada bidang penghalang kaca dan coran adalah memiliki redaman yang besar sedangkan kayu tidak. Harapan penelitian ini dapat digunakan sebagai acuan untuk mendirikan bangun ruang dengan fasilitas jaringan internet dan dapat dikembangkan oleh penelitian berikutnya yang berhubungan dengan gelombang elektromagnet.
\end{abstract}

Kata kunci: Gelombang Elektromagnet, Massa Jenis, Wireless Fidelty, USB WiFi

\section{PENDAHULUAN}

Dalam sistem komunikasi nirkabel (wireless), energi elektromagnetis dipancarkan ke media transmisi menggunakan antena yang berfungsi sebagai radiator. Wi-fi (Wireless Fidelity) adalah koneksi tanpa kabel seperti handphone dengan mempergunakan teknologi radio sehingga pemakaiannya dapat mentransfer data dengan cepat. Wi-fi tidak hanya dapat digunakan untuk mengakses internet, Wi-fi juga dapat digunakan untuk membuat jaringan tanpa kabel di perusahaan. Karena itu banyak orang mengasosiasikan Wi-Fi dengan kebebasan karena teknologi Wi-Fi ditujukan untuk pengunaan perangkat nirkabel dan jaringan Area Lokal (LAN), namun saat ini lebih banyak digunakan untuk mengakses internet. Hal ini memungkinkan seseorang dengan kartu nirkabel (wireless card) atau personal digital assistant (PDA) untuk terhubung dengan internet dengan menggunakan titik akses (atau dikenal dengan hotspot) terdekat.

Fading adalah fenomena yang terjadi pada kanal nirkabel. Sinyal komunikasi pada kanal nirkabel yang berpropagasi dari pemancar menuju penerima dapat menempuh banyak jalur, sehingga fenomena ini disebut propagasi multipath. Propagasi multipath menimbulkan fluktuasi pada amplitudo, fasa, dan sudut datang sinyal yang tiba dipenerima sehingga menimbulkan istilah multipath fading. Di daerah perkotaan, banyaknya bangunan tinggi yang menghalangi jalur antara antena pemancar dan penerima menjadi timbulnya fading. Banyaknya penghalang tersebut mengakibatkan sinyal yang tiba di antena penerima bukan hanya sinyal LOS tetapi juga sinyal yang telah mengalami pantulan oleh permukaan tanah, gedung atau objek lainnya.

Penelitian disebuah gedung sekolah SMP, SMA, SMK Dewi Sartika yang berlokasi Jalan Kebon Nanas Utara II No. 23 Kelurahan Cipinang Cempedak Kecamatan Jatinegara Jakarta Timur. Dimana sekolah tersebut memiliki jaringan internet dengan media Wireless Fidelty yang terpasang di beberapa ruang kelas, kantor, perpustakaan, ruang lab komputer, dan kantin dengan topologi tree. Dimana siswa dan karyawan sekolah adalah sebagai pengguna Wireless Fidelty tersebut dengan beberapa masalah 
dikarenakan pemasangan titik - titik Access Point yang bertujuan semua pengguna dapat terjangkau.

\section{LANDASAN TEORI}

A. Gelombang Elektromagnetik

Gelombang elektromagnetik adalah perambatan osilasi medan listrik dan medan magnet seperti diilustrasikan pada gambar 2.1. Medan listrik di simbolkan dengan $E$ dan medan magnetik disimbolkan dengan $B$.

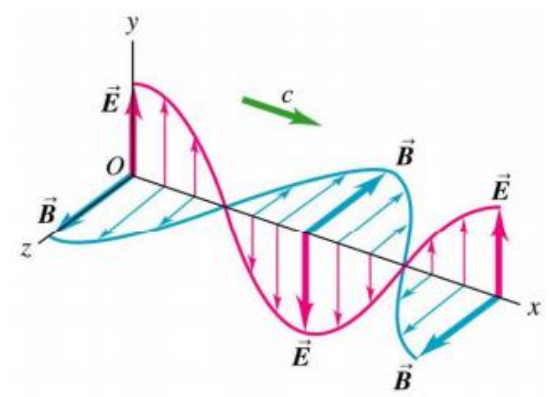

Gambar 1. Ilustrasi osilasi medan listrik dan megnet pada gelombangelektromagnetik.

(sumber: Ebook Fisika Dasar II. Mikrajuddin Abdullah, ITB. 2017)

Gelombang elektromagnetik dapat merambat dalam ruang hampa atau medium tertentu. Sampainya cahaya matahari dan bintang-bintang ke bumi menunjukkan kemampuan gelombang elektromagnetik merambat dalam ruang hampa. Cahaya yang menembus air dan gelas menunjukkan kemampuan perambatan gelombang elektromagnetik dalam sejumlah bahan. Tetapi tidak semua bahan dapat dilewati gelombang elektromagnetik. Logam adalah contoh bahan yang tidak dapat dilewati gelombang elektromagnetik.[1]

Dalam ruang hampa atau dalam medium yang tidak memiliki sifat magnetik, arah osilasi medan listrik dan medan magnet tegak lurus arah rambat. Jadi dalam ruang hampa atau dalam medium non magnetik, gelombang elektromagnetik merupakan gelombang transfersal. Tetapi dalam medium magnetik, gelombang elektromagnetik tidak selalu transversal. Berdasarkan Hukum Faraday, James Clerk Maxwell mengemukakan Hipotesa sebagai berikut: "Perubahan Medan Listrik dapat menimbulkan medan magnet". Hipotesa ini sudah teruji dan disebut dengan Teori Maxwell. Inti Teori Maxwell mengenai gelombang elektromagnetik adalah:

1. Perubahan Medan Listrik dapat menghasilkan medan magnet.

2. Cahaya termasuk gelombang elektromagnetik.
B. Laju perambatan gelombang elektromagnetik Gelombang elektromagnetik adalah gelombang yang merambat dengan laju yang sangat tinggi. Dalam ruang hampa, laju perambatan gelombang elektromagnetik memenuhi persamaan.

$$
C_{o}=\frac{1}{\sqrt{\mu_{o} \varepsilon_{o}}}
$$

di mana

$\mu_{o}$ adalah permeabilitas ruang hampa $=$ $4 \pi \times 10^{-7} \mathrm{~N} / \mathrm{A}^{2}$

$\varepsilon_{o}$ adalah permitivitas ruang hampa

$=8,854 \times 10^{-12} \mathrm{~F} / \mathrm{m}$

Dengan memasukan nilai tersebut maka laju gelombang elektromagnetik dalam ruang hampa adalah

$$
C_{o}=2,99792458 \times 10^{8} \mathrm{~m} / \mathrm{s}
$$

Yang sering kali dibulatkan menjadi $3 \times$ $10^{8} \mathrm{~m} / \mathrm{s}$. Laju perambaan geombang elektromagnetik dalam ruang hampa merupakan batas maksimum laju yang dapat dicapai di alam semesta. Sebagai ilustrasi, dalam satu detik, gelombang elektromagnetik dapat mengelilingi bumisebanyak 7,5 kali. Dalam medium, laju perambatan gelombang elektromagnetik berkurang. Dalam intan cahaya, yang merupakan salah satu jenis gelombang elektromagnetik merambat dengan laju $1,24 \times 10^{8} \mathrm{~m} / \mathrm{s}$.[2]

Di dalam material, laju perambatan gelombang elektromagnetik lebih kecil dari pada dalam ruang hampa. Secara umum, laju perambatan gelombang elektromagnetik dalam material memenuhi persamaan

$$
c=\frac{1}{\sqrt{\mu_{r} \mu_{o} K \varepsilon_{o}}}
$$

di mana

$\mu_{r}$ disebut permeabilitas relative material

$K$ disebut konstanta dielektrik material

\section{Spektrum gelombang elektromagnetik}

Gelombang elektromagnetik merupakan gelombang dengan sebaran frekuensi yang paling luas. Frekuensi gelombang elektromagnetik tersebar mulai dari $10^{2} \mathrm{~Hz}$ sampai di atas $10^{23} \mathrm{~Hz}$. Hubungan antara laju, frekuensi, dan panjang gelombang diberikan oleh

$$
c=\lambda f
$$

dengan $\lambda$ panjang gelombang dan $f$ frekuensi. 


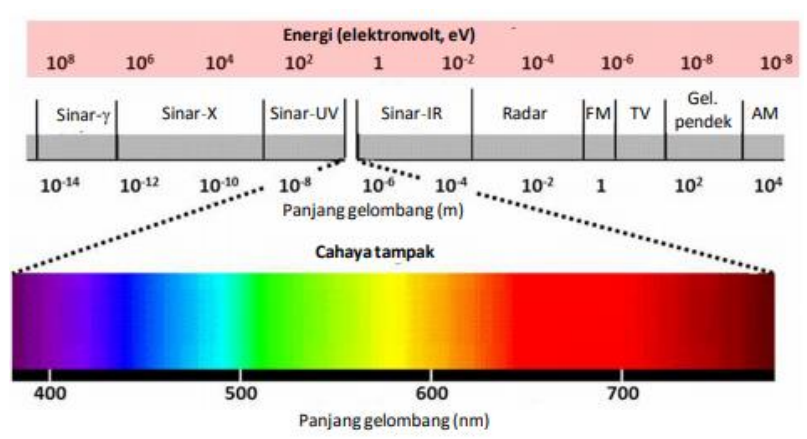

Gambar 2. Spektrum gelombang elektromagnetik (sumber: Ebook Fisika Dasar II. Mikrajuddin Abdullah, ITB. 2017)

Jangkauan frekuensi gelombang elekromagnetik yang sangat lebar tersebut dikelompokkan atas sejumlah spectrum yang memiliki bidang aplikasi berbeda - beda. Gambar 2. adalah pembagian kelompok gelombang elektromagnetik yang disepakati saat ini.

\section{Massa Jenis}

Massa jenis dapat diartikansebagai kerapatan suatu zat, yaitu massa benda per satuan volume. Selain itu bahwa pada zat yang sama dengan wujud yang berbeda memiliki massa jenis yang sama, dan pada zat yang berbeda massa jenisnya berbeda pula. Untuk benda yang memiliki volume kecil massa jenis didefinisikan sebagai

$$
\rho=\frac{m}{V}
$$

Dengan $m$ massa, $V$ volume fluida, dan $\rho$ massa jenis benda. Tabel 1. adalah massa jenis beberapa benda. Persamaan (4) setiap zat selalu memiliki massa dan volume. Massa zat dapat diukur dengan timbangan atau neraca. Volume zat dapat diukur dengan rumus atau menggunakan gelas ukur dan gelas pancuran. [3]

Tabel 1. Massa jenis benda

\begin{tabular}{|c|c|c|}
\hline $\begin{array}{c}\text { Bahan atau } \\
\text { Zat }\end{array}$ & $\begin{array}{c}\text { Massa Jenis } \\
\left(\mathbf{K g} / \mathbf{m}^{\mathbf{3}}\right)\end{array}$ & $\begin{array}{c}\text { Massa Jenis } \\
\left(\mathbf{g} / \mathbf{c m}^{\mathbf{3}}\right)\end{array}$ \\
\hline Emas & 19.300 & 19,3 \\
\hline Raksa & 13.600 & 13,6 \\
\hline Platina & 21.450 & 21,45 \\
\hline Timah & 11.400 & 11,4 \\
\hline Baja & 8.000 & 8,0 \\
\hline Perak & 10.500 & 10,5 \\
\hline Kuningan & 8.400 & 8,4 \\
\hline Besi & 7.900 & 7,9 \\
\hline Seng & 7.140 & 7,14 \\
\hline Titanium & 4.500 & 4,5 \\
\hline Aluminium & 2.700 & 2,7 \\
\hline Fiberglas & 2.000 & 2,0 \\
\hline Air & 1.000 & 1,0 \\
\hline $\begin{array}{c}\text { Minyak } \\
\text { Tanah }\end{array}$ & 800 & 0,8 \\
\hline
\end{tabular}

E.Wireless Fidelity

Wi-Fi (Wireless Fidelity) adalah koneksi tanpa kabel seperti handphone dengan mempergunakan teknologi radio sehingga pemakaiannya dapat mentransfer data dengan cepat. $W i-F i$ tidak hanya dapat digunakan untuk mengakses internet, $W i-F i$ juga dapat digunakan untuk membuat jaringan tanpa kabel di perusahaan. Karena itu banyak orang mengasosiasikan $W i-F i$ dengan kebebasan karena teknologi $W i-F i$ memberikan kebebasan kepada pemakaianya untuk mengakses internet atau mentransfer data dari ruang meeting, kamar hotel, kampus, dan café- café yang bertanda Wi-Fi Hot Spot. Awalnya $\mathrm{Wi}-\mathrm{Fi}$ ditujukan untuk pengunaan perangkat nirkabel dan Jaringan Area Lokal (LAN), namun saat ini lebih banyak digunakan untuk mengakses internet. Hal ini memungkinkan seseorang dengan komputer yang menggunakan kartu nirkabel (wireless card) atau personal digital assistant (PDA) untuk terhubung dengan internet dengan menggunakan titik akses (atau dikenal dengan hotspot) terdekat.

$W i-F i$ dirancang berdasarkan spesifikasi IEEE 802.11. Sekarang ini ada empat variasi dari 802.11, yaitu: 802.11a, 802.11b, 802.11g, dan 802.11n. Spesifikasi b merupakan produk pertama $W i-F i$. Variasi g dan n merupakan salah satu produk yang memiliki penjualan terbanyak pada 2005.[4]

Tabel 2. Spesifikasi Wi-Fi

\begin{tabular}{|c|c|c|c|}
\hline Spesifikasi & Kecepatan & Frekuensi & Band \\
\hline $802.11 \mathrm{~b}$ & $11 \mathrm{Mb} / \mathrm{s}$ & $2.4 \mathrm{GHz}$ & B \\
\hline $802.11 \mathrm{a}$ & $54 \mathrm{Mb} / \mathrm{s}$ & $5 \mathrm{GHz}$ & A \\
\hline $802.11 \mathrm{~g}$ & $54 \mathrm{Mb} / \mathrm{s}$ & $2.4 \mathrm{GHz}$ & b, g \\
\hline $802.11 \mathrm{n}$ & $100 \mathrm{Mb} / \mathrm{s}$ & $2.4 \mathrm{GHz}$ & $\mathrm{b}, \mathrm{g}, \mathrm{n}$ \\
\hline
\end{tabular}

Secara teknis operasional, Wi-Fi merupakan salah satu varian teknologi komunikasi dan informasi yang bekerja pada jaringan dan perangkat WLAN (wireless local area network). Dengan kata lain, $W i-F i$ adalah sertifikasi merek dagang yang diberikan pabrikan kepada perangkat telekomunikasi (internet) yang bekerja di jaringan WLAN dan sudah memenuhi kualitas kapasitas interoperasi yang dipersyaratkan. Teknologi internet berbasis Wi-Fi dibuat dan dikembangkan sekelompok insinyur Amerika Serikat yang bekerja pada Institute of Elektrical and Elektronis Engineers (IEEE) berdasarkan standar teknis perangkat bernomor 802.11b, 
802.11a dan 802.16. Perangkat Wi-Fi sebenarnya tidak hanya mampu bekerja di jaringan WLAN, tetapi juga di Jaringan Wireless Metropolitan Area Network (WMAN).

Prangkat dengan standar teknis $802.11 \mathrm{~b}$ diperuntukkan bagi perangkat WLAN pada frekuensi $2,4 \mathrm{GHz}$ atau yang lazim disebut frekuensi ISM (Industrial, Scientific, and Edical). Sedangkan untuk perangkat yang berstandar teknis 802.11a dan 802.16 diperuntukkan bagi perangkat WMAN atau juga disebut Wi-Max, yang bekerja di sekitar pita frekuensi $5 \mathrm{GHz}$.

\section{METODE PENELITIAN}

Kegiatan penelitian Analisa Tebal Tembus Gelombang Elektronagnet dalam uji coba pengukuran dan perhitungan dilakukan dalam kurun waktu bulan April 2019 sampai dengan bulan Juli 2019. Dengan metode - metode dalam penelitian ini adalah sebagai berikut;

\section{A. Studi literatur}

Penulis dalam kegiatan ini menerapkan metode studi literatur yaitu dengan berusaha mempelajari materi dasar - dasar pengetahuan yang bersesuaian dari buku - buku, artikel, bahan - bahan kuliah, buletin dan journal dengan tahapan pertama memahami gelombang elektromagnetik dan bagaimana sifat - sifat gelombang elektromagnet dan perhitunganya. Tahapan kedua mempelajari media bidang halang dengan menghitung massa jenis dan kerapatan bidang. Tahapan ketiga mempelajari alat pembangkit gelombang elektromagnet, prinsip kerja, cara kerja, dan mengetahui hasil pengukuran dengan menggunakan aplikasi pada laptop.

\section{B. Bimbingan dan konsultasi}

Penulis akan selalu menjadwalkan pertemuan kepada dosen pembimbing agar mendapatkan arahan yang tepat dan jelas untuk membantu saat kegiatan penelitian menganalisa tebal bidang gelombang elektromagnet sesuai dengan yang di harapkan.

\section{Studi Lapangan (eksperiment)}

Untuk kegiatan penelitian tebal bidang tembus gelombang elektromagnet dengan mengumpulkan alat dan bahan seperti laptop 2 buah dengan operating sistem keluarga windows, sediakan alat Wireless 802.11n USB Adapter LVUW03 sebanyak 2 buah yang akan difungsikan sebagai teransmiter dan receiver, kemudian menyediakan bahan bidang penghalang yang berbeda jenis seperti; beton, kayu, dan kaca, dengan berbeda - beda dimensi dengan variabel ketebalan untuk Beton/coran dalam cm ( 5, 10,
15), untuk kayu multiplek dalam $\mathrm{cm}(0,6 ; 1,2 ; 2)$ dan kaca dalam $\mathrm{cm}(0,3 ; 0,6 ; 1)$.

Langkah kerja mengukur bidang tembus gelombang elektromagnet

a. Instalasikan pada masing - masing laptop dan USB Wireless 802.11n adapter LV-UW03.

b. Hidupkan laptop 1 dan laptop 2, aktifkan aplikasi Connectify Hotspot 2019 untuk memfungsikan adapter Wi-Fi di laptop 1 sebagai transmiternya dan mengaktifkan adpater Wi-Fi di laptop 2 sebagai Receiver, kemudia menguji koneksi internet dan melihat berapa daya yang di terima tanpa penghalang.

c. Tentukan jarak transmiter pada laptop 1 dengan receiver pada laptop 2 sesuai dengan ketebalan bidang penghalang sesuai variabel yang sudah di sediakan dimana jarak untuk transmitter dan receiver dengan penghalang sejauh $0 \mathrm{~cm}$.

d. Mulai melakukan penelitian dengan memasukan data pada tabel pengukuran daya, dan terus mengulang langkah kerja dari menentukan jarak transmiter dan receiver sampai bahan sudah di ujikan semua.

e. Langkah selanjutnya penulis melakukan perhitungan sesuai dengan dimensi bidang penghalang antara transmiter dan receiver dengan jarak penghalang $0 \mathrm{~cm}$, dan dimasukan ke dalam tabel penghitungan.

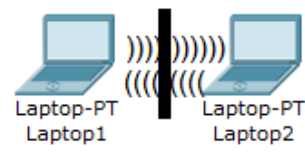

Gambar 3. Ilustrasi topologi peer to peer dengan penghalang

\section{HASIL DAN PEMBAHASAN \\ A. Pengukuran volume dan massa jenis bidang Kayu, Kaca, dan Cor}

Pada pengukuran volume penulis mempersiapkan alat dan bahan terlebih dahulu dengan mengunakan alat ukur penggaris standar dan timbangan menghitung menggunakan persamaan fisika dasar:
$\mathrm{V}=\mathrm{P} \times \mathrm{L} \times \mathrm{T}$
Dimana:
$\mathrm{V}$ adalah volume dengan $\left(\mathrm{cm}^{3}\right)$
$\mathrm{P}$ adalah panjang bidang $(\mathrm{cm})$
$\mathrm{L}$ adalah lebar bidang $(\mathrm{cm})$
$\mathrm{T}$ adalah tinggi bidang $(\mathrm{cm})$ 
Tabel 3 Hasil Pengukuran dan Perhitungan Volume

\begin{tabular}{|c|c|c|c|c|c|}
\hline No & $\begin{array}{c}\text { Jenis } \\
\text { Bidang }\end{array}$ & $\begin{array}{c}\text { Panjang } \\
(\mathrm{cm})\end{array}$ & $\begin{array}{c}\text { Lebar } \\
(\mathrm{cm})\end{array}$ & $\begin{array}{c}\text { Tinggi } \\
(\mathrm{cm})\end{array}$ & $\begin{array}{c}\text { Volume } \\
\left(\mathrm{cm}^{3}\right)\end{array}$ \\
\hline \multirow{3}{*}{1} & \multirow{3}{*}{ Kayu } & 35 & 0,6 & 35 & 735 \\
\cline { 3 - 6 } & & 45 & 1,2 & 25 & 1.260 \\
\hline \multirow{3}{*}{2} & \multirow{3}{*}{ Kaca } & 55 & 2 & 30 & 3.300 \\
\cline { 3 - 6 } & & 28 & 0,3 & 25 & 210 \\
\hline \multirow{3}{*}{3} & \multirow{3}{*}{ Coran } & 28 & 1 & 25 & 700 \\
\cline { 3 - 6 } & & 25 & 5 & 25 & 3.125 \\
\cline { 3 - 6 } & & 25 & 10 & 25 & 6.250 \\
\hline & & & & 25 & 9.375 \\
\hline
\end{tabular}

Dari Tabel 3 Hasil pengukuran dan perhitungan volume bidang dapat diketahui bahwa dari masing - masing bahan dengan lebar atau ketebalan yg berbeda beda dan mendapatkan volume yang berbeda - beda seperti untuk kayu dengan lebar $0,6 \mathrm{~cm}, 1,2 \mathrm{~cm}$, dan $2 \mathrm{~cm}$ menghasilkan volume kayu $735 \mathrm{~cm}^{3}, 1.260 \mathrm{~cm}^{3}$, dan $3.300 \mathrm{~cm}^{3}$. Untuk bidang kaca dengan lebar $0,3 \mathrm{~cm}, 0,6 \mathrm{~cm}$, dan $1 \mathrm{~cm}$ menghasilkan volume kaca $210 \mathrm{~cm}^{3}, 420 \mathrm{~cm}^{3}$, dan $700 \mathrm{~cm}^{3}$. Sedangkan untuk bidang coran/beton dengan lebar 5 $\mathrm{cm}, 10 \mathrm{~cm}$, dan $15 \mathrm{~cm}$ menghasilkan $3.125 \mathrm{~cm}^{3}, 6.250$ $\mathrm{cm}^{3}$, dan $9.375 \mathrm{~cm}^{3}$.

Dengan persamaan volume, penulis melanjutkan mengukur dan menghitung massa jenis dengan persamaan

$$
\rho=\frac{m}{V}
$$

\section{Dimana:}

$\rho$ adalah massa jenis bidang gram $/ \mathrm{cm}^{3}$

$m$ adalah berat jenis bidang gram

$V$ adalah volume bidang $\mathrm{cm}^{3}$

Dari persamaan massa jenis dapat dihasilkan dari bidang kayu, kaca dan coran sebagai berikut:

Tabel 4 Hasil pengukuran dan perhitungan massa jenis

\begin{tabular}{|c|c|c|c|c|}
\hline \multirow{3}{*}{ No } & \multirow{2}{*}{$\begin{array}{c}\text { Nama } \\
\text { Bidang }\end{array}$} & $\begin{array}{c}\text { Berat } \\
\text { Jenis } \\
(\mathrm{gram})\end{array}$ & $\begin{array}{c}\text { Volume } \\
\left(\mathrm{cm}^{3}\right)\end{array}$ & $\begin{array}{c}\text { Massa Jenis } \\
\left(\mathrm{gram} / \mathrm{cm}^{3}\right)\end{array}$ \\
\hline \multirow{3}{*}{1.} & \multirow{3}{*}{ Kayu } & 230 & 735 & 0,313 \\
\cline { 3 - 5 } & & 450 & 1.260 & 0,357 \\
\cline { 3 - 5 } & & 1.715 & 3.300 & 0,519 \\
\hline \multirow{3}{*}{2.} & \multirow{3}{*}{ Kaca } & 470 & 210 & 2,238 \\
\hline \multirow{3}{*}{3.} & \multirow{3}{*}{ Coran } & 940 & 420 & 2,238 \\
\cline { 3 - 5 } & & 1.910 & 700 & 2,728 \\
\cline { 3 - 5 } & & 4.500 & 3.125 & 1,440 \\
\cline { 3 - 5 } & & 1.000 & 6.250 & 1,760 \\
\hline
\end{tabular}

Dari Tabel 4 Hasil pengukuran dan perhitungan massa jenis atau rapat jenis di ketahui untuk bidang kayu memiliki massa jenis yang berbeda beda sesuai dengan berat 230 gram, 450 gram, dan 1.715 gram menghasilkan massa jenis sebesar $0,313 \mathrm{gram} / \mathrm{cm}^{3}$, $0,357 \mathrm{gram} / \mathrm{cm}^{3}$ dan $0,519 \mathrm{gram} / \mathrm{cm}^{3}$. Kemudian untuk bidang kaca dengan berat 470gram, 940 gram, dan 1.910 gram menghasilkan massa jenis sebesar 2,238 gram $/ \mathrm{cm}^{3}, 2,238 \mathrm{gram} / \mathrm{cm}^{3}$, dan $2,728 \mathrm{gram} / \mathrm{cm}^{3}$. Sedangkan untuk bidang coran/ beton dengan berat 4.500 gram, 11.000 gram, dan 17.500 gram menghasilkan massa jenis sebesar $1,440 \mathrm{gram} / \mathrm{cm}^{3}$, $1,760 \mathrm{gram} / \mathrm{cm}^{3}$, dan $1,867 \mathrm{gram} / \mathrm{cm}^{3}$

\section{B. Pengukuran signal input dan output pada LV-UW03}

Pada pengukuran signal Output dan input, penulis mempersiapkan alat dan bahan yaitu dua buah laptop yang berkerja sebagai transmitter dan receiver dengan terinstalasi USB WiFi LV-UW03 yang mendapatkan sumber tegangan dari USB sebesar 5 Volt DC dan sesuai dengan spesifikasi USB wireless LV-UW03 memiliki power transmit wireless sebesar $20 \mathrm{dBm}$.Yang dirangkai seperti Gambar 4.1 dimana Laptop toshiba sebagai transmitter dan laptop HP sebagai receiver.

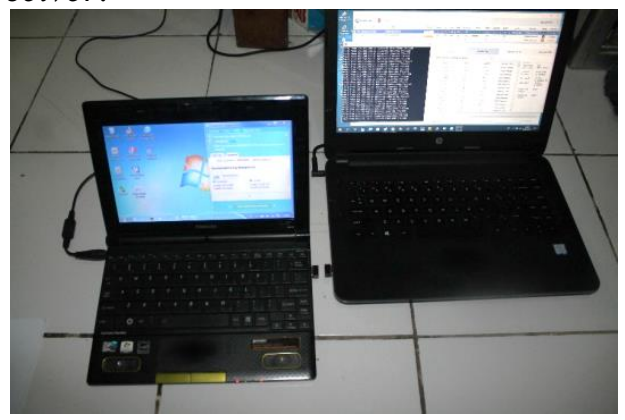

Gambar 4 Laptop yang terpasang USB Wireless LV-UW03 (Sumber: Dokumen Pribadi)

Dalam pengujian pertama yaitu dengan bidang berbahan kayu dengan ketebalan $0,6 \mathrm{~cm}$. untuk dapat membandingkan nilai output dan input, maka penulis melakukan dengan 2 kali percobaan yaitu percobaan pertama tanpa penghalang dengan ukuran sesuai dengan tebal bidang yaitu $0,6 \mathrm{~cm}$ sebagai jarak antara USB wireless Transmitter dan receiver dengan rentangan waktu dimana penulis mencatat perubahan signal yang diterima selama 5detik sekali. Dan status akses point sudah terkoneksi dan memanggil data dari receiver ke transmitter dengan cara ping ip address transmitter. 


\section{Percobaan 1 bidang kayu dengan ketebalan 0,6 cm}

Tabel 5 percobaan 1 bidang kayu dengan 0,6 cm ketebalan

\begin{tabular}{|c|c|c|}
\hline $\begin{array}{c}\text { Waktu } \\
(5 \text { detik })\end{array}$ & $\begin{array}{c}\text { Tanpa penghalang } \\
(\mathrm{dB})\end{array}$ & $\begin{array}{c}\text { Dengan penghalang } \\
(\mathrm{dB})\end{array}$ \\
\hline 5 & -21 & -21 \\
\hline 10 & -21 & -21 \\
\hline 15 & -21 & -23 \\
\hline 20 & -21 & -24 \\
\hline 25 & -21 & -25 \\
\hline 30 & -21 & -25 \\
\hline 35 & -21 & -26 \\
\hline 40 & -21 & -25 \\
\hline 45 & -21 & -24 \\
\hline 50 & -21 & -24 \\
\hline Rata2 & -21 & $-23,8$ \\
\hline
\end{tabular}

Hasil pengukuran hambatan bidang kayu multiplek dengan ketebalan $0,6 \mathrm{~cm}$, panjang $35 \mathrm{~cm}$, dan lebar $35 \mathrm{~cm}$ dengan dimensi $735 \mathrm{~cm}^{3}$, massa jenis $0,313 \mathrm{gram} / \mathrm{cm}^{3}$. Proses pengukuran dapat dilihat Tabel 5 dengan per 5 detik penulis mencatat dengan daya signal yang diukur tanpa penghalang dengan jarak 0,6 cm menghasilkan -21dB dan setelah detik ke 50 penulis meletakan penghalang antara transmitter dengan receiver waktu per 5 detik penulis mendapatkan rata - rata daya signal menurun menjadi $-23,8 \mathrm{~dB}$. Dan memiliki simpangan baku pada hasil menggunakan penghalang sebesar 1,42. Selisih hambatan pada bidang kayu dengan ketebalan $0,6 \mathrm{~cm}$ sebesar 2,8 dB.

Grafik percobaan 1 Bidang Kayu dengan 0,6 cm

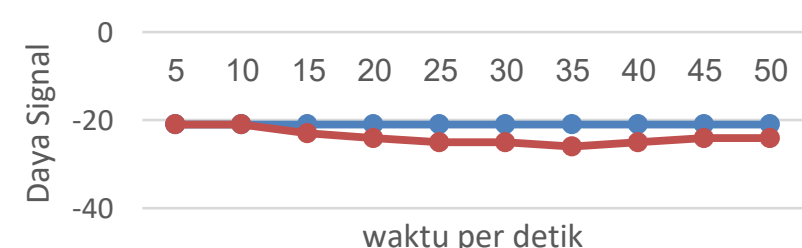

waktu per detik

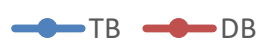

Gambar 5 Grafik percobaan 1 Bidang Kayu dengan 0,6 cm

\section{Percobaan 2 bidang kayu dengan ketebalan 1,2 cm}

Tabel 6 Percobaan 2 bidang kayu dengan 1,2 cm ketebalan

\begin{tabular}{|c|c|c|}
\hline $\begin{array}{c}\text { Waktu (5 } \\
\text { detik) }\end{array}$ & $\begin{array}{c}\text { Tanpa penghalang } \\
(\mathrm{dB})\end{array}$ & $\begin{array}{c}\text { Dengan penghalang } \\
(\mathrm{dB})\end{array}$ \\
\hline 5 & -21 & -21 \\
\hline 10 & -21 & -21 \\
\hline 15 & -21 & -24 \\
\hline 20 & -22 & -25 \\
\hline 25 & -21 & -26 \\
\hline 30 & -22 & -27 \\
\hline
\end{tabular}

\begin{tabular}{|c|c|c|}
\hline 35 & -23 & -28 \\
\hline 40 & -21 & -28 \\
\hline 45 & -22 & -25 \\
\hline 50 & -22 & -27 \\
\hline Rata2 & $-21,6$ & $-25,2$ \\
\hline
\end{tabular}

Pada hasil pengukuran hambatan bidang kayu multiplek dengan ketebalan $1,2 \mathrm{~cm}$, panjang $45 \mathrm{~cm}$ dan lebar $25 \mathrm{~cm}$ dengan dimensi $1.260 \mathrm{~cm}^{3}$, massa jenis $0,357 \mathrm{gram} / \mathrm{cm}^{3}$. Proses pengukuran dapat dilihat pada Tabel 6 dengan per 5 detik penulis mencatat dengan daya signal yang diukur tanpa penghalang dengan jarak 1,2 cm menghasilkan rata - rata -21,6 dB dan setelah detik 50 penulis meletakan penghalang antara transmitter dengan receiver dalam per 5 detik penulis mendapatkan rata - rata daya signal menurun menjadi $-25,2 \mathrm{~dB}$. Dan memiliki simpangan baku sebesar 3,31. Selisih hambatan pada bidang kayu dengan ketebalan sebesar 3,6 dB.

\section{Grafik percobaan 2 Bidang Kayu dengan 1,2 cm}

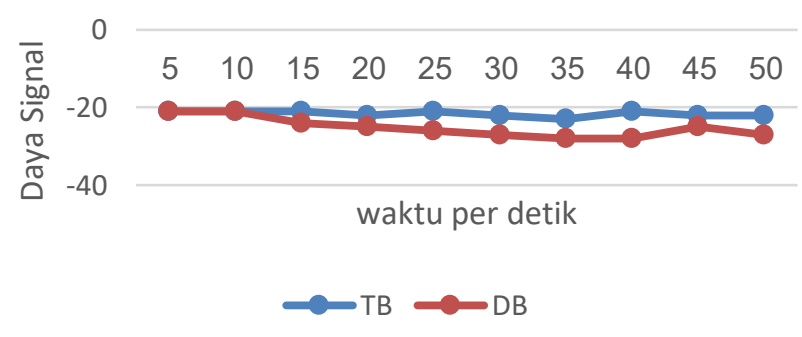

Gambar 6 Grafik percobaan 2 Bidang kayu dengan 1,2 cm

Percobaan 3 bidang kayu dengan ketebalan $2 \mathrm{~cm}$

Tabel 7 Percobaan 3 bidang kayu dengan $2 \mathrm{~cm}$ ketebalan

\begin{tabular}{|c|c|c|}
\hline $\begin{array}{c}\text { Waktu (5 } \\
\text { detik) }\end{array}$ & $\begin{array}{c}\text { Tanpa penghalang } \\
(\mathrm{dB})\end{array}$ & $\begin{array}{c}\text { Dengan penghalang } \\
(\mathrm{dB})\end{array}$ \\
\hline 5 & -25 & -25 \\
\hline 10 & -25 & -25 \\
\hline 15 & -24 & -25 \\
\hline 20 & -24 & -30 \\
\hline 25 & -24 & -30 \\
\hline 30 & -24 & -29 \\
\hline 35 & -23 & -29 \\
\hline 40 & -23 & -29 \\
\hline 45 & -23 & -29 \\
\hline 50 & -23 & -29 \\
\hline Rata2 & $-23,8$ & -28 \\
\hline
\end{tabular}

Pada hasil pengukuran hambatan bidang kayu multiplek dengan ketebalan $2 \mathrm{~cm}$, panjang $55 \mathrm{~cm}$ dan lebar $30 \mathrm{~cm}$ dengan dimensi $3.300 \mathrm{~cm}^{3}$, massa jenis $0,520 \mathrm{gram} / \mathrm{cm}^{3}$. Proses pengukuran dapat dilihat pada Tabel 7 dengan per 5 detik penulis mencatat dengan daya signal yang diukur tanpa penghalang dengan jarak $2 \mathrm{~cm}$ menghasilkan rata - rata $-23,8 \mathrm{~dB}$ dan setelah detik 50 penulis meletakan penghalang antara transmitter dengan receiver dalam per 5 detik penulis mendapatkan rata - rata daya signal menurun menjadi 
-28 dB. Dan memiliki simpangan baku sebesar 2,22. Selisih hambatan pada bidang kayu dengan ketebalan $2 \mathrm{~cm}$ sebesar $4,2 \mathrm{~dB}$

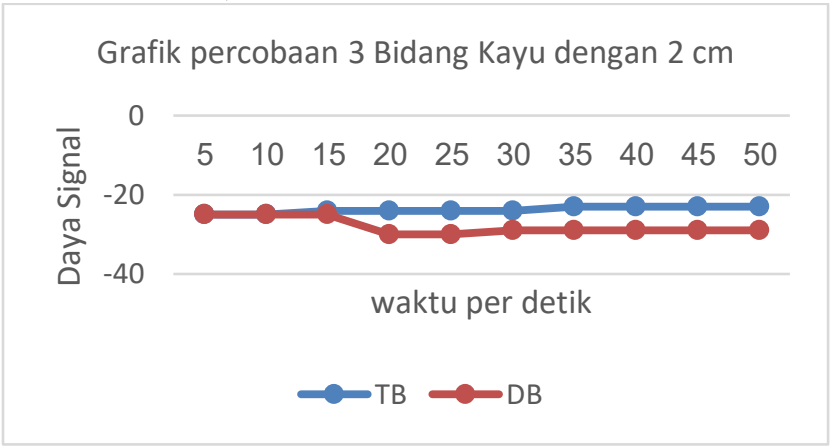

Gambar 7 Grafik percobaan 3 bidang kayu dengan $2 \mathrm{~cm}$

\section{Percobaan 1 bidang kaca dengan ketebalan $0,3 \mathrm{~cm}$}

Tabel 8 Percobaan 1 bidang kaca dengan $0,3 \mathrm{~cm}$ ketebalan

\begin{tabular}{|c|c|c|}
\hline $\begin{array}{c}\text { Waktu (5 } \\
\text { detik) }\end{array}$ & $\begin{array}{c}\text { Tanpa penghalang } \\
(\mathrm{dB})\end{array}$ & $\begin{array}{c}\text { Dengan penghalang } \\
(\mathrm{dB})\end{array}$ \\
\hline 5 & -21 & -26 \\
\hline 10 & -21 & -27 \\
\hline 15 & -21 & -27 \\
\hline 20 & -21 & -25 \\
\hline 25 & -21 & -27 \\
\hline 30 & -21 & -28 \\
\hline 35 & -21 & -28 \\
\hline 40 & -21 & -29 \\
\hline 45 & -21 & -31 \\
\hline 50 & -21 & -27 \\
\hline Rata2 & -21 & $-27,5$ \\
\hline
\end{tabular}

Hasil pengukuran hambatan bidang kaca dengan ketebalan $0,3 \mathrm{~cm}$, panjang $28 \mathrm{~cm}$, dan lebar 25 $\mathrm{cm}$ dengan dimensi $210 \mathrm{~cm}^{3}$, massa jenis 1,741 gram $/ \mathrm{cm}^{3}$. Proses pengukuran dapat dilihat Tabel 8 dengan per 5 detik penulis mencatat dengan daya signal yang diukur tanpa penghalang dengan jarak 0,3 cm menghasilkan $-21 \mathrm{~dB}$ dan setelah detik ke 50 penulis meletakan penghalang antara transmitter dengan receiver waktu per 5 detik penulis mendapatkan rata - rata daya signal menurun menjadi -27,5 dB. Dan memiliki simpangan baku sebesar 1,36. Selisih hambatan pada bidang kaca sebesar 6,5 dB.

Grafik percobaan 1 Bidang Kaca dengan 0,3 cm

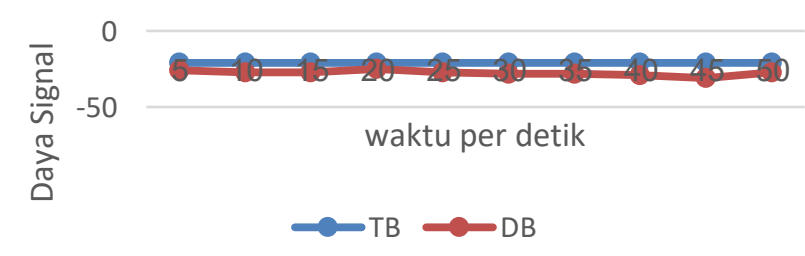

Gambar 8 Grafik percobaan 1 bidang kaca dengan 0,3 cm
Percobaan 2 bidang kaca dengan ketebalan $0,6 \mathrm{~cm}$

Tabel 9 Percobaan 2 bidang kaca dengan 0,6 cm ketebalan

\begin{tabular}{|c|c|c|}
\hline $\begin{array}{c}\text { Waktu (5 } \\
\text { detik) }\end{array}$ & $\begin{array}{c}\text { Tanpa penghalang } \\
(\mathrm{dB})\end{array}$ & $\begin{array}{c}\text { Dengan penghalang } \\
(\mathrm{dB})\end{array}$ \\
\hline 5 & -21 & -21 \\
\hline 10 & -21 & -22 \\
\hline 15 & -21 & -26 \\
\hline 20 & -21 & -31 \\
\hline 25 & -21 & -32 \\
\hline 30 & -21 & -36 \\
\hline 35 & -21 & -34 \\
\hline 40 & -21 & -36 \\
\hline 45 & -21 & -37 \\
\hline 50 & -21 & -35 \\
\hline Rata2 & -21 & -31 \\
\hline
\end{tabular}

Pada hasil pengukuran hambatan bidang kaca dengan ketebalan 0,6 cm, panjang $28 \mathrm{~cm}$ dan lebar 25 $\mathrm{cm}$ dengan dimensi $420 \mathrm{~cm}^{3}$, massa jenis 2,238 $\mathrm{gram} / \mathrm{cm}^{3}$. Proses pengukuran dapat di lihat pada Tabel 9 dengan per 5 detik penulis mencatat dengan daya signal yang di ukur tanpa penghalang dengan jarak 0,6 cm menghasilkan rata - rata $-21 \mathrm{~dB}$ dan setelah detik 50 penulis meletakan penghalang antara transmitter dengan receiver dalam per 5 detik penulis mendapatkan rata - rata daya signal menurun menjadi -31 dB. Dan memiliki simpangan baku sebesar 17,67. Selisih hambatan pada bidang kaca dengan ketebalan $0,6 \mathrm{~cm}$ sebesar $10 \mathrm{~dB}$.

\section{Grafik percobaan 2 Bidang Kaca dengan 0,6} $\mathrm{cm}$

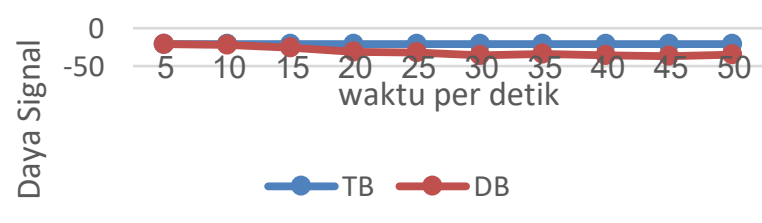

Gambar 9 Grafik percobaan 2 bidang kaca dengan 0,6 cm

\section{Percobaan 3 bidang kaca dengan ketebalan 1 cm}

Tabel 10 Percobaan 3 bidang kaca dengan $1 \mathrm{~cm}$ ketebalan

\begin{tabular}{|c|c|c|}
\hline $\begin{array}{c}\text { Waktu (5 } \\
\text { detik) }\end{array}$ & $\begin{array}{c}\text { Tanpa penghalang } \\
(\mathrm{dB})\end{array}$ & $\begin{array}{c}\text { Dengan penghalang } \\
(\mathrm{dB})\end{array}$ \\
\hline 5 & -21 & -24 \\
\hline 10 & -21 & -22 \\
\hline 15 & -21 & -24 \\
\hline 20 & -21 & -35 \\
\hline 25 & -21 & -38 \\
\hline 30 & -21 & -38 \\
\hline 35 & -21 & -40 \\
\hline 40 & -21 & -44 \\
\hline 45 & -21 & -36 \\
\hline 50 & -21 & -30 \\
\hline Rata2 & -21 & $-33,1$ \\
\hline
\end{tabular}


Pada hasil pengukuran hambatan bidang kaca dengan ketebalan $1 \mathrm{~cm}$, panjang $28 \mathrm{~cm}$ dan lebar 25 $\mathrm{cm}$ dengan dimensi $700 \mathrm{~cm}^{3}$, massa jenis 2,728 gram $/ \mathrm{cm}^{3}$. Proses pengukuran dapat dilihat pada Tabel 10 dengan per 5 detik penulis mencatat dengan daya signal yang diukur tanpa penghalang dengan jarak 1 $\mathrm{cm}$ menghasilkan rata - rata $-21 \mathrm{~dB}$ dan setelah detik 50 penulis meletakan penghalang antara transmitter dengan receiver dalam per 5 detik penulis mendapatkan rata - rata daya signal menurun menjadi $-33,1$ dB. Dan memiliki simpangan baku sebesar 29,16. Selisih hambatan pada bidang kaca sebesar $12,1 \mathrm{~dB}$.

\section{Grafik percobaan 3 Bidang Kaca dengan $1 \mathrm{~cm}$}

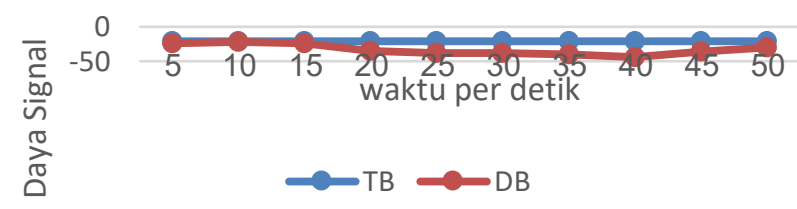

Gambar 10 Grafik percobaan 3 bidang kaca dengan $1 \mathrm{~cm}$

\section{Percobaan 1 bidang coran dengan ketebalan $5 \mathrm{~cm}$}

Tabel 11 Percobaan 1 bidang coran dengan $5 \mathrm{~cm}$ ketebalan

\begin{tabular}{|c|c|c|}
\hline $\begin{array}{c}\text { Waktu (5 } \\
\text { detik) }\end{array}$ & $\begin{array}{c}\text { Tanpa penghalang } \\
(\mathrm{dB})\end{array}$ & $\begin{array}{c}\text { Dengan penghalang } \\
(\mathrm{dB})\end{array}$ \\
\hline 5 & -41 & -44 \\
\hline 10 & -41 & -49 \\
\hline 15 & -41 & -53 \\
\hline 20 & -41 & -54 \\
\hline 25 & -41 & -53 \\
\hline 30 & -41 & -51 \\
\hline 35 & -41 & -49 \\
\hline 40 & -41 & -49 \\
\hline 45 & -41 & -51 \\
\hline 50 & -41 & -49 \\
\hline Rata2 & -41 & $-50,2$ \\
\hline
\end{tabular}

Hasil pengukuran hambatan bidang Cor dengan ketebalan $5 \mathrm{~cm}$, panjang $25 \mathrm{~cm}$, dan lebar $25 \mathrm{~cm}$ dengan dimensi $3.125 \mathrm{~cm}^{3}$, massa jenis 1,440 $\mathrm{gram} / \mathrm{cm}^{3}$. Proses pengukuran dapat di lihat Tabel 11 pada lampiran dengan per 5 detik penulis mencatat dengan daya signal yang di ukur tanpa penghalang dengan jarak $5 \mathrm{~cm}$ menghasilkan $-41 \mathrm{~dB}$ dan setelah detik ke 50 penulis meletakan penghalang antara transmitter dengan receiver waktu per 5 detik penulis mendapatkan rata - rata daya signal menurun menjadi $-50,2 \mathrm{~dB}$. Dan memiliki simpangan baku sebesar 4,2. Selisih hambatan pada bidang Cor sebesar 9,2 dB.

\section{Grafik percobaan 1 Bidang Cor dengan $5 \mathrm{~cm}$}

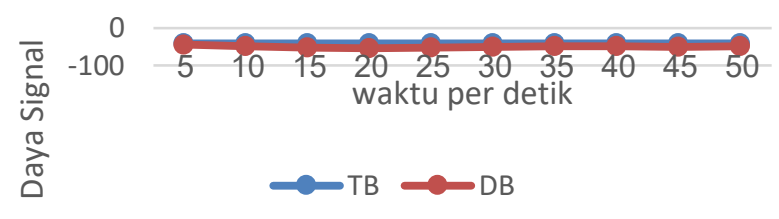

Gambar 11 Grafik percobaan 1 bidang coran dengan $5 \mathrm{~cm}$

Percobaan 2 bidang coran dengan ketebaln $10 \mathrm{~cm}$

Tabel 12 Percobaan 2 bidang coran dengan $10 \mathrm{~cm}$ ketebalan

\begin{tabular}{|c|c|c|}
\hline $\begin{array}{c}\text { Waktu (5 } \\
\text { detik) }\end{array}$ & $\begin{array}{c}\text { Tanpa penghalang } \\
(\mathrm{dB})\end{array}$ & $\begin{array}{c}\text { Dengan penghalang } \\
(\mathrm{dB})\end{array}$ \\
\hline 5 & -49 & -52 \\
\hline 10 & -49 & -52 \\
\hline 15 & -49 & -52 \\
\hline 20 & -49 & -52 \\
\hline 25 & -49 & -53 \\
\hline 30 & -49 & -53 \\
\hline 35 & -49 & -54 \\
\hline 40 & -49 & -65 \\
\hline 45 & -49 & -65 \\
\hline 50 & -49 & -65 \\
\hline Rata2 & -49 & $-63,3$ \\
\hline
\end{tabular}

Pada hasil pengukuran hambatan bidang coran dengan ketebalan $10 \mathrm{~cm}$, panjang $25 \mathrm{~cm}$ dan lebar $25 \mathrm{~cm}$ dengan dimensi $6.250 \mathrm{~cm}^{3}$, massa jenis $1,760 \mathrm{gram} / \mathrm{cm}^{3}$. Proses pengukuran dapat dilihat pada Tabel 12, setiap 5 detik penulis mencatat dengan daya signal yang diukur tanpa penghalang dengan jarak $10 \mathrm{~cm}$ menghasilkan rata - rata $-49 \mathrm{~dB}$ dan setelah detik 50 penulis meletakan penghalang antara transmitter dengan receiver dalam per 5 detik penulis mendapatkan rata - rata daya signal menurun menjadi $-63,3 \mathrm{~dB}$. Dan memiliki simpangan baku sebesar 18,23. Selisih hambatan pada bidang Cor sebesar 14,3 $\mathrm{dB}$

\section{Grafik percobaan 2 Bidang Cor dengan $10 \mathrm{~cm}$}

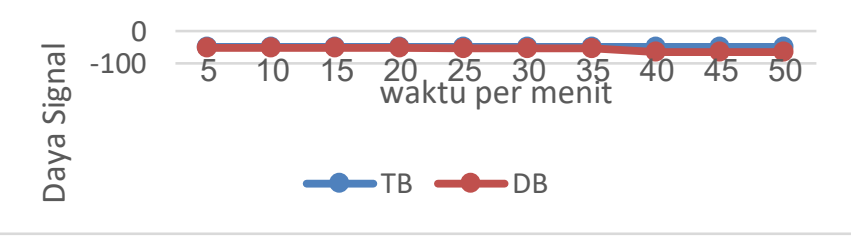

Gambar 12 Grafik percobaan 2 bidang coran dengan 10 $\mathrm{cm}$ 
Percobaan 3 bidang coran ketebal $15 \mathrm{~cm}$

Tabel 13 Percobaan 3 bidang coran $15 \mathrm{~cm}$ ketebalan

\begin{tabular}{|c|c|c|}
\hline $\begin{array}{c}\text { Waktu (5 } \\
\text { detik) }\end{array}$ & $\begin{array}{c}\text { Tanpa penghalang } \\
(\mathrm{dB})\end{array}$ & $\begin{array}{c}\text { Dengan penghalang } \\
(\mathrm{dB})\end{array}$ \\
\hline 5 & -55 & -70 \\
\hline 10 & -55 & -70 \\
\hline 15 & -55 & -70 \\
\hline 20 & -55 & -72 \\
\hline 25 & -55 & -73 \\
\hline 30 & -55 & -77 \\
\hline 35 & -55 & -77 \\
\hline 40 & -55 & -77 \\
\hline 45 & -55 & -78 \\
\hline 50 & -55 & -79 \\
\hline Rata2 & -55 & $-74,3$ \\
\hline
\end{tabular}

Pada hasil pengukuran hambatan bidang coran dengan ketebalan $15 \mathrm{~cm}$, panjang $25 \mathrm{~cm}$ dan lebar $25 \mathrm{~cm}$ dengan dimensi $9.375 \mathrm{~cm}^{3}$, massa jenis $1,867 \mathrm{gram} / \mathrm{cm}^{3}$. Proses pengukuran dapat di lihat pada Tabel 13 pada lampiran dengan per 5 detik penulis mencatat dengan daya signal yang di ukur tanpa penghalang dengan jarak $10 \mathrm{~cm}$ menghasilkan rata - rata $-55 \mathrm{~dB}$ dan setelah detik 50 penulis meletakan penghalang antara transmitter dengan receiver dalam per 5 detik penulis mendapatkan rata - rata daya signal menurun menjadi $-74,3 \mathrm{~dB}$. Dan memiliki simpangan baku sebesar 6,67 Selisih hambatan pada bidang Cor sebesar 19,3dB

Grafik percobaan 3 Bidang Cor dengan $15 \mathrm{~cm}$

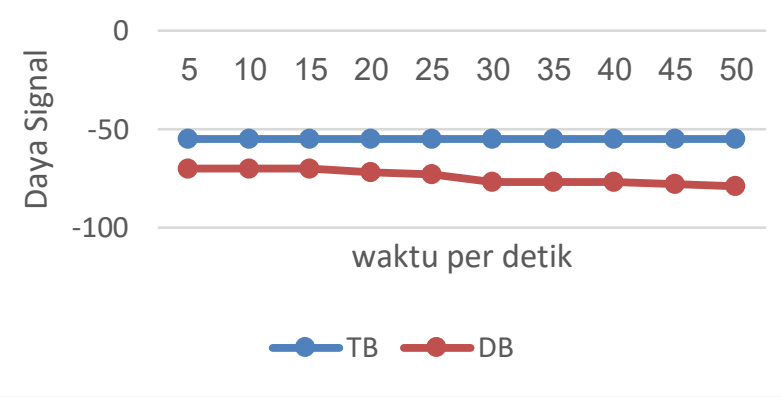

Gambar 13 Grafik percobaan 3 bidang coran ketebalan 15 $\mathrm{cm}$

Dari pengukuran dan perhitungan mendapatkan hasil seperti tabel 3 dari hasil tersebut penulis dapat menarik kesimpulan perbandingan antara nama nama bidang diuji dari bidang kayu, kaca, dan coran. Dengan dimensi berbeda beda sesuai dengan bahan bidang dan massa jenis yang terhitung.
Tabel 14. Tabel hasil pengukuran dan perhitungan

\begin{tabular}{|c|c|c|c|c|c|c|c|c|}
\hline No. & $\begin{array}{c}\text { Nama } \\
\text { Bidang }\end{array}$ & $\begin{array}{c}\text { Tebal } \\
(\mathrm{cm})\end{array}$ & $\begin{array}{c}\text { Daya } \\
\text { In } \\
(\mathrm{dB})\end{array}$ & $\begin{array}{c}\text { Dimensi } \\
(\text { PxLxT) } \\
\left(\mathrm{cm}^{3}\right)\end{array}$ & $\begin{array}{c}\text { Massa Jenis } \\
\left(\mathrm{gram} / \mathrm{cm}^{3}\right)\end{array}$ & $\begin{array}{c}\text { Daya } \\
\text { Out } \\
(\mathrm{dB})\end{array}$ & $\begin{array}{c}\text { Simpangan } \\
\text { baku }\end{array}$ & $\begin{array}{c}\text { Attenuasi } \\
(\mathrm{dB})\end{array}$ \\
\hline 1 & $\begin{array}{c}\text { Kayu } \\
\text { Multiplek }\end{array}$ & 0,6 & -21 & 735 & 0,313 & $-23,8$ & 1,42 & 2,8 \\
\hline 2 & $\begin{array}{c}\text { Kayu } \\
\text { Multiplek }\end{array}$ & 1,2 & $-21,6$ & 1.260 & 0,357 & $-25,2$ & 3,31 & 3,6 \\
\hline 3 & $\begin{array}{c}\text { Kayu } \\
\text { Multiplek }\end{array}$ & 2 & $-23,8$ & 3.300 & 0,520 & -28 & 2,22 & 4,2 \\
\hline 4 & Kaca & 0,3 & -21 & 210 & 1,741 & $-27,5$ & 1,36 & 6,5 \\
\hline 5 & Kaca & 0,6 & -21 & 420 & 2,238 & -31 & 17,67 & 10 \\
\hline 6 & Kaca & 1 & -21 & 700 & 2,728 & $-33,1$ & 29,16 & 12,1 \\
\hline 7 & Cor/Beton & 5 & -41 & 3.125 & 1,440 & $-50,2$ & 4,2 & 9,2 \\
\hline 8 & Cor/Beton & 10 & -49 & 6.250 & 1,760 & $-63,3$ & 18,23 & 14,3 \\
\hline 9 & Cor/Beton & 15 & -55 & 9.375 & 1,867 & $-74,3$ & 6,67 & 19,3 \\
\hline
\end{tabular}

Dari perhitungan dan pengukuran pada tabel 14 menunjukan pada bidang kayu terukur dengan tebal $0,6 \mathrm{~cm}$ dengan volume $735 \mathrm{~cm}^{3}$ dan massa jenis 0,313 mendapatkan $-21 \mathrm{~dB}$ saat tanpa penghalang, $-23,8 \mathrm{~dB}$ dengan penghalang, memiliki simpangan baku 1,42 dan redaman 2,8 dB. Pada bidang kayu terukur dengan tebal $1,2 \mathrm{~cm}$ dengan volume $1.260 \mathrm{~cm}^{3}$ dan massa jenis 0,357 mendapatkan -21,6 dB saat tanpa penghalang, 25,2 $\mathrm{dB}$ dengan penghalang, memiliki simpangan baku 3,31 dan redaman 3,6 dB. Sedangkan pada bidang kayu terukur dengan tebal $2 \mathrm{~cm}$ dengan volume $3.300 \mathrm{~cm}^{3}$ dan massa jenis 0,520 mendapatkan $-23,8$ $\mathrm{dB}$ saat tanpa penghalang, $-28 \mathrm{~dB}$ dengan penghalang, memiliki simpangan baku 2,22 dan redaman 4,2 dB.

Dari perhitungan dan pengukuran pada tabel 14 menunjukan pada bidang kaca terukur dengan tebal $0,3 \mathrm{~cm}$ dengan volume $210 \mathrm{~cm}^{3}$ dan massa jenis 1,741 mendapatkan $-21 \mathrm{~dB}$ saat tanpa penghalang, $-27,5 \mathrm{~dB}$ dengan penghalang, memiliki simpangan baku 1,36 dan redaman $6,5 \mathrm{~dB}$. Pada bidang kaca terukur dengan tebal $0,6 \mathrm{~cm}$ dengan volume $420 \mathrm{~cm}^{3}$ dan massa jenis 2,238 mendapatkan -21 dB saat tanpa penghalang, -31 $\mathrm{dB}$ dengan penghalang, memiliki simpangan baku 17,67 dan redaman $10 \mathrm{~dB}$. Sedangkan pada bidang kaca terukur dengan tebal $1 \mathrm{~cm}$ dengan volume 700 $\mathrm{cm}^{3}$ dan massa jenis 2,728 mendapatkan $-21 \mathrm{~dB}$ saat tanpa penghalang, -33,1 dB dengan penghalang, memiliki simpangan baku 29,16 dan redaman 12,1 dB.

Dari perhitungan dan pengukuran pada tabel 14 menunjukan pada bidang coran terukur dengan tebal $5 \mathrm{~cm}$ dengan volume $3.125 \mathrm{~cm}^{3}$ dan massa jenis 1,440 mendapatkan $-41 \mathrm{~dB}$ saat tanpa penghalang, 50,2 dB dengan penghalang, memiliki simpangan baku 4,2 dan redaman 9,2 dB. Pada bidang coran terukur dengan tebal $10 \mathrm{~cm}$ dengan volume $6.250 \mathrm{~cm}^{3}$ dan massa jenis 1,760 mendapatkan $-49 \mathrm{~dB}$ saat tanpa penghalang, -63,3 dB dengan penghalang, memiliki simpangan baku 18,23 dan redaman 14,3 dB. Sedangkan pada bidang coran terukur dengan tebal 15 
cm dengan volume $9.375 \mathrm{~cm}^{3}$ dan massa jenis 1,867 mendapatkan $-55 \mathrm{~dB}$ saat tanpa penghalang, -74,3 dB dengan penghalang, memiliki simpangan baku 6,67 dan redaman 19,3 dB.

\section{SIMPULAN}

Pada bidang kayu adalah bidang penghambat yang lemah menyerap daya signal, sedangkan bidang penghalang dengan bahan kaca dan Cor memiliki bidang hambatan yang kuat menyerap daya signal. Dan penulis dapat menyarankan kepada pihak sekolah SMK Dewi Sartika untuk menambahkan akses point yang akan diletakan tidak melewati penghalang dengan redaman yang besar seperti tembok dan kaca. Semoga penelitian ini sebagai bahan acuan untuk penelitian selanjutnya.

\section{KEPUSTAKAAN}

[1] S. Rahayu and H. Akhsan, "Pengembangan panduan praktikum perangkat gelombang mikro pada materi gelombang elektromagnetik di program studi pendidikan fisika fkip unsri."

[2] Suharyanto. Karyono. Dwi Satya Palupi, Pusat Perbukuan Departemen Pendidikan Nasional, Jilid 3. Jakarta: CV. SAHABAT, 2009.

[3] M. Abdullah, FISIKA DASAR 1. Bandung, 2016.

[4] R. Hartono and A. Purnomo, "Wireless Network 802.11,” 2011. 